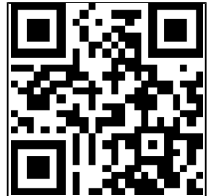

Editor's choice to access m free content

\title{
Interventions with potential to reduce sedentary time in adults: systematic review and meta-analysis
}

\author{
Anne Martin, ${ }^{1}$ Claire Fitzsimons, ${ }^{1}$ Ruth Jepson, ${ }^{2}$ David H Saunders, ${ }^{1}$ \\ Hidde P van der Ploeg, ${ }^{3}$ Pedro J Teixeira, ${ }_{1}^{4}$ Cindy M Gray, ${ }^{5}$ Nanette Mutrie, ${ }^{1}$ on behalf \\ of the EuroFIT consortium
}

- Additional material is published online only. To view please visit the journal online (http://dx.doi.org/10.1136/ bjsports-2014-094524)

${ }^{1}$ Physical Activity for Health Research Centre (PAHRC), Institute for Sport, Physical Education and Health Sciences, University of Edinburgh,

Edinburgh, UK

${ }^{2}$ Centre for Population Health Sciences, Scottish Collaboration for Public Health Research and Policy, University of Edinburgh, Edinburgh, UK

${ }^{3}$ Department of Public and Occupational Health, EMGO Institute for Health and Care Research, VU University Medical Center Amsterdam, Amsterdam, The Netherlands ${ }^{4}$ Department of Sports and Health, Faculty of Human Kinetics, Interdisciplinary Centre for the Study of Human Performance (CIPER), University of Lisbon, Lisbon, Portugal ${ }^{5}$ Institute of Health and Wellbeing, University of Glasgow, Glasgow, UK

\section{Correspondence to} Professor Nanette Mutrie, Physical Activity for Health Research Centre (PAHRC), Institute for Sport, Physical Education and Health Sciences, University of Edinburgh, Holyrood Road, Edinburgh EH8 8AQ, UK:

Nanette.Mutrie@ed.ac.uk

Accepted 8 February 2015

Published Online First

23 April 2015

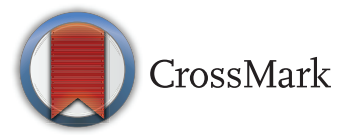

To cite: Martin $A_{\text {, }}$ Fitzsimons $C$, Jepson $\mathrm{R}$, et al. Br J Sports Med 2015:49:1056-1063.

\section{ABSTRACT}

Context Time spent in sedentary behaviours (SB) is associated with poor health, irrespective of the level of physical activity. The aim of this study was to evaluate the effect of interventions which included SB as an outcome measure in adults.

Methods Thirteen databases, including The Cochrane Library, MEDLINE and SPORTDiscus, trial registers and reference lists, were searched for randomised controlled trials until January 2014. Study selection, data extraction and quality assessment were performed independently. Primary outcomes included SB, proxy measures of SB and patterns of accumulation of SB. Secondary outcomes were cardiometabolic health, mental health and body composition. Intervention types were categorised as SB only, physical activity (PA) only, PA and SB or lifestyle interventions (PA/SB and diet).

Results Of 8087 records, 51 studies met the inclusion criteria. Meta-analysis of 34/51 studies showed a reduction of $22 \mathrm{~min} /$ day in sedentary time in favour of the intervention group $(95 \% \mathrm{Cl}-35$ to $-9 \mathrm{~min} /$ day, $\mathrm{n}=5868)$. Lifestyle interventions reduced SB by $24 \mathrm{~min} /$ day $(95 \% \mathrm{Cl}-41$ to $-8 \mathrm{~min} /$ day, $n=3981$, moderate quality) and interventions focusing on SB only by $42 \mathrm{~min} /$ day $(95 \% \mathrm{Cl}-79$ to $-5 \mathrm{~min} /$ day, $n=62$, low quality). There was no evidence of an effect of PA and combined PA/SB interventions on reducing sedentary time.

Conclusions There was evidence that it is possible to intervene to reduce SB in adults. Lifestyle and SB only interventions may be promising approaches. More high quality research is needed to determine if SB interventions are sufficient to produce clinically meaningful and sustainable reductions in sedentary time.

\section{INTRODUCTION}

There is growing public health concern about the amount of time spent in sedentary behaviours (SB). SB are defined as behaviours where sitting or lying is the dominant posture and energy expenditure is very low. ${ }^{1}$ Sedentary time accumulates daily while commuting, at work, at home and during leisure time. ${ }^{2}$ Where studies have controlled for the influence of moderate-to-vigorous physical activity (MVPA), too much time spent in SB is associated with poor health, including elevated cardiometabolic risk markers, type 2 diabetes and premature mortality. ${ }^{3-9}$ Where studies have controlled for the influence of total sedentary and moderate-to-vigorous activity time, increased breaks in sedentary time have been shown to be beneficially associated with waist circumference, body mass index (BMI), triglycerides and $2 \mathrm{~h}$ plasma glucose. ${ }^{10}$ Interventions interrupting extended sitting with frequent short activity breaks have enhanced markers of cardio metabolic health. ${ }^{11-13}$

Recent systematic reviews have summarised the literature in respect to health implications, ${ }^{14-18}$ measurement, ${ }^{19}$ prevalence, ${ }^{20}$ correlates $^{21}$ and interventions in young people. ${ }^{22}$ To date, only one review of the evidence on interventions to influence total SB in adults has been published. ${ }^{23}$ The review concluded that interventions with a specific goal of increasing PA levels and those which combined an increase in PA levels with a decrease in sedentary time resulted in modest reductions in SB, while interventions focusing on $\mathrm{SB}$ only resulted in greater reduction of sedentary time. The present systematic review expands this existing evidence ${ }^{23}$ in five ways: (1) evaluating intervention effects using more precise categories of interventions; (2) assessing effects on pattern of SB accumulation; (3) conducting subgroup analyses; (4) including only randomised controlled trials (RCTs); and (5) assessing effects on health outcomes.

The primary aim of this review was to evaluate the effect of interventions which included an SB outcome measure in adults. The secondary aim was to determine the effects of interventions, which included an SB outcome, on measures of health.

\section{METHODS}

The protocol for this review is available online at the International Prospective Register for Systematic Reviews. $^{24}$

\section{Study selection criteria}

Studies were eligible for inclusion if they met the following criteria:

Study design: RCTs

Population: Adults aged 18 years or more who have left school.

Intervention: Any intervention which included an SB outcome measure in free-living adults was eligible; those in clinical settings such as hospitals were excluded. Eligible control conditions were no intervention, waiting list, attention control (eg, general health information), usual care (eg, diabetes treatment involving lifestyle counselling) and alternative treatment conditions (eg, a structured exercise programme).

Outcomes: Studies reporting any of the following outcomes were included:

- Objectively measured SB obtained from accelerometers 
- Objectively measured sitting time obtained from inclinometers

- Objectively or self-reported patterns of accumulation of SB

- Self-reported total sitting time

- Self-reported proxy measures of sitting time where it is not certain that people are sitting (eg, screen time and transport time) and proxy measures of overall SB (eg, occupational sitting time)

Other inclusion criteria: Only full text articles published in the English language were included in this review.

\section{Data sources and searches}

In January 2014, the Cochrane Central Register of Controlled Trials (Issue 12 of 12 December 2013), MEDLINE (1946-November week 3 2013), EMBASE (1980-week 1 2014), PsycINFO (1806-November week 5 2013), SPORTDiscus (1975-7 January 2014), CINAHL (1937-7 January 2013), Cochrane Database of Systematic Reviews (Issue 1 of 12 January 2014), Database of Health Promotion Research (Biblomap, Issue 4 of 4, October 2013), Database on Obesity and SB Studies (16 January 2014), Conference Proceedings Citation Indexes (Web of Science, 1900 to current), controlled-trials.com (16 January 2014), WHO International Clinical Trial Registry (16 January 2014) and the Networked Digital Library of Theses and Dissertations (1900-current) were searched. The search strategy for MEDLINE is listed in online supplementary 1. Reference lists and citations of relevant studies were examined and experts in the field contacted for details of ongoing and unpublished studies.

\section{Study selection}

At least two reviewers independently screened the titles/abstracts (AM, RJ) and full text articles (AM and RJ, CF or DHS). Eligibility disagreements were resolved by a third reviewer (NM).

\section{Data extraction and quality assessment}

Duplicate data extraction was performed independently for $10 \%$ of the included studies (AM and RJ, CF or DHS) and discrepancies resolved through discussion. The following secondary outcomes for this review were recorded from included studies:

- Biomarkers of cardiometabolic risk including blood glucose levels, blood lipid levels, total cholesterol levels, glycosylated haemoglobin, blood pressure

- Mental health outcomes including depression and anxiety

- Objectively obtained BMI, waist circumference and/or fat mass.

The full list of extracted data items can be obtained from the study protocol. ${ }^{24}$

Quality of all studies was assessed by two reviewers (AM, DHS) using the Tool for Assessing Risk of Bias from the Cochrane Collaboration. $^{25}$ Risk of bias was scored as 'high', 'unclear' or 'low' for the following domains: (1) participant selection bias, (2) intervention performance bias, (3) effect detection bias, (4) outcome reporting bias, (5) attrition bias and (6) bias due to comparability of baseline groups.

Publication bias was examined using a funnel plot whenever meta-analyses included 10 or more studies. ${ }^{25}$

Quality of evidence for primary outcomes was assessed using the GRADEpro software developed by the Grading of Recommendations Assessment Development and Evaluation (GRADE) Working Group. ${ }^{26}$ An overall quality score is based on the assessment of risk of bias, indirectness, imprecision, inconsistency and publication bias of primary outcomes. The GRADE Working Group grades of evidence are high, moderate, low and very low quality.

\section{Data synthesis and analysis}

Studies reporting similar outcome measures were combined in meta-analyses using random effects models to account for intervention heterogeneity. Where suitable data were not reported, efforts were made to obtain the data from study authors. To account for variability between studies, inverse variance was used, giving more weight for studies with less variability. Effect sizes were estimated as mean differences ( $\mathrm{min} /$ day) between the intervention and control groups. Review Manager 5.2 was used for quantitative analysis. ${ }^{27}$

For cluster RCTs where control of clustering was missing, intervention effects were approximately corrected by reducing the sample size of each trial to its 'effective sample size'. The sample size was divided by the design effect, which is $[1+(\mathrm{M}-1) \times \mathrm{ICC}]$, where $\mathrm{M}$ is the average of cluster size and ICC is the intracluster correlation coefficient. ${ }^{25}$ An ICC of 0.01 was used.

Where suitable data were available, studies were combined in a meta-analysis regardless of whether missing data were imputed by authors. Variation in the degree of missing data was considered as a potential source of heterogeneity of results. A sensitivity analysis to examine the effect of inclusion of complete cases on robustness of intervention effects was performed.

Further heterogeneity of findings was assessed by comparing similarity of included studies in terms of study design, participants, interventions, outcomes and study quality. The cause of heterogeneity was evaluated by conducting subgroup and sensitivity analyses. Statistical heterogeneity was assessed by calculating the $\mathrm{I}^{2}$ statistic indicating the variability of the intervention effect due to heterogeneity. Variability of more than $50 \%$ may indicate moderate to substantial heterogeneity of intervention effects according to the Cochrane Handbook. ${ }^{25}$

Subgroup analyses within this review focused on:

- Intervention type (SB, PA/SB or lifestyle which, in addition to $\mathrm{PA} / \mathrm{SB}$, also included a dietary/nutrition component)

- Gender (men, women, men and women)

- Intervention duration ( $<3$ months, 3-6 months, $>6$ months)

- Follow-up duration (<3 months, 3-6 months, 7-12 months, $>12$ months)

- Intervention setting (work place vs home/community)

- Outcome measurement tool (objective measurement tool, sitting time self-report, proxy measurement tool)

- Study aim (SB as a primary vs secondary study aim)

Sensitivity analyses were used to test the effect of including studies which were cluster designs, used usual care or alternative treatment control groups, or were at 'high risk' of performance and attrition bias.

Included studies lacking data suitable for meta-analysis are described narratively.

\section{RESULTS}

\section{Results of the literature search}

Figure 1 displays the PRISMA diagram of the literature search. Inclusion criteria were met by 57 records which comprised 51 studies. Thirty-six studies provided adequate data to be included in meta-analyses.

\section{Characteristics of included studies}

Study and participant characteristics are summarised in table 1 of the online supplementary material. Of the 51 included studies (18 480 participants), 44 were $\mathrm{RCTs}^{28-70}$ and seven were cluster RCTs $^{71-77}$ conducted in Europe $(n=25)$, the USA $(n=18)$, Australia $(n=7)$ and China $(n=1)$. The majority of studies were carried out in a mixed gender population $(n=35) ; 13$ studies 
Figure 1 PRISMA diagram of the literature search results.

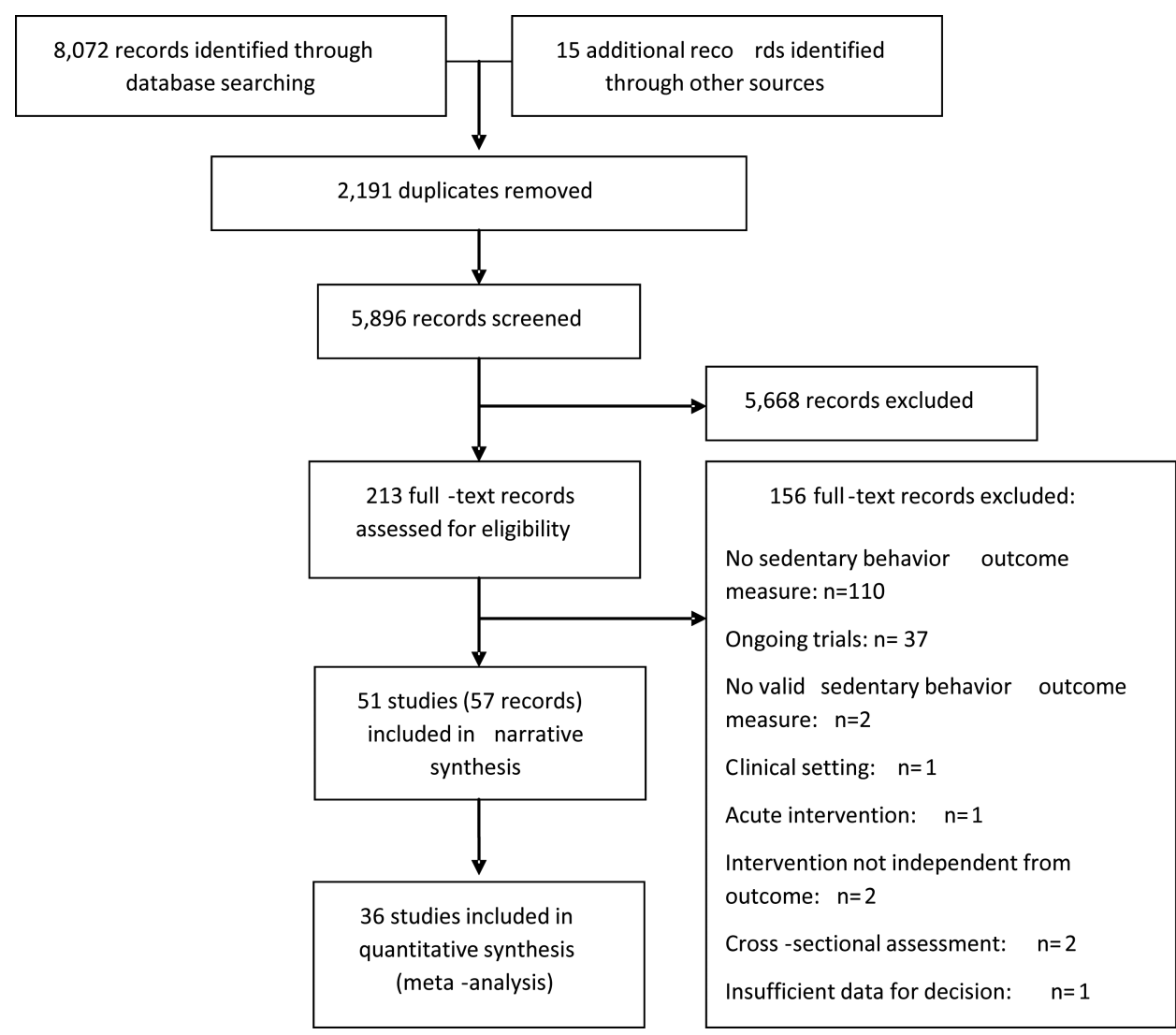

targeted women only 294250515657606167697176 and three studies targeted men only. ${ }^{29} 3144$ Most studies included participants aged between $18-60$ years $(n=44)$, while seven studies included participants older than 60 years of age. ${ }^{33} 353738486272$ Twenty-three studies were conducted in overweight or obese adults, five studies in participants with type 2 diabetes mellitus and three studies in participants with high levels of cardiovascular risk factors. Two studies were conducted in pregnant women.

Types of intervention and control conditions varied substantially between included studies (see online supplementary table S1). Three studies employed an intervention specifically to reduce $\mathrm{SB}^{40} 44 \quad 63 \quad 16$ studies aimed at increasing PA levels, ${ }^{30} \begin{array}{lllllllllllllll}35 & 36 & 39 & 41 & 46 & 48 & 49 & 55 & 58-60 & 64 & 66 & 72 & 78 & \text { nine studies }\end{array}$ combined both approaches of reducing SB and increasing PA levels, ${ }^{32} 4353626568707677$ one study assessed the effect of a dietary intervention on $\mathrm{SB},{ }^{61}$ and 22 studies (20 reports) applied a multicomponent lifestyle intervention and observed effects on sedentary behaviour (among other outcomes). $293334373842454750-$ 52545657676971737475 Twenty studies offered an alternative intervention, 3036 39-41 $45464952-555961-6368727710$ studies the usual/routine care, ${ }^{29} 373842505167717475$ seven studies used a waiting list control, ${ }^{29} 344864697678$ five studies an attention control, $^{35} 44565760$ and control participants of seven studies received no intervention at all. ${ }^{32} 33434758667073$

\section{Risk of bias of included studies}

Figure 2 shows each risk of bias item presented as percentages across all included studies.

\section{Selection bias}

Correct randomisation was used in $65 \%$ of the studies (33/51), and therefore there was low risk of bias in these studies. However, for the remaining studies, insufficient details were reported and thus assessed as 'unclear'. In nearly 70\% (35/51) of the studies, there was lack of reporting on whether or not participants knew in advance their group allocation, and thus there was an unclear risk of bias. For studies that provided information, studies were judged to be at low risk of allocation concealment bias.

\section{Performance bias}

It is recognised that in lifestyle interventions it is not possible to blind participants and researchers delivering the intervention to group allocation and this creates high risk of bias. However, $67 \%(34 / 51)$ of included studies were considered at low risk of performance bias because SB was not the primary outcome. A further $31 \%(16 / 51)$ of included studies were judged to be at high risk of performance bias because the participants and researchers delivering the intervention were not blinded to the purpose of the intervention, which was reducing SB. Risk of performance bias was unclear for one study ${ }^{33}$ due to insufficient information provided.

\section{Detection bias}

Sixty-one per cent of the studies (31/51) assessed SB through self-reports and thus were at high risk for detection bias. The risk of cross-contamination was 'low' in half of the studies and 'unclear' in the other half.

\section{Attrition bias}

The issue of incomplete outcome data was sufficiently addressed in $47 \%(24 / 51)$ of the studies, and thus these studies were at low risk of attrition bias. However, 43\% (22/51) of the studies did not account for missing data and thus were at high risk of attrition bias. Five studies were at 'unclear' risk of attrition bias.

\section{Comparability of baseline groups}

Over $50 \%(29 / 51)$ of the studies were at low risk of bias. Apparent flaws in the randomisation process were found in 
Table 1 Intervention effects for change of sedentary behaviour by subgroups

\begin{tabular}{|c|c|c|c|}
\hline Subgroup & Studies & Participants & $\begin{array}{l}\text { Intervention effect } \\
\left(\min / \text { day), } \mathrm{MD}\left(95 \% \mathrm{Cl}, \mathrm{I}^{2}\right)\right.\end{array}$ \\
\hline \multicolumn{4}{|l|}{ Sex* } \\
\hline Men & 2 & 434 & $-57.94(-86.14$ to $-29.74 ; 0 \%)$ \\
\hline Women & 10 & 1541 & $-5.97(-23.51$ to $11.57 ; 33 \%)$ \\
\hline Men/women & 22 & 3893 & $-25.32(-42.94$ to $-7.69 ; 83 \%)$ \\
\hline \multicolumn{4}{|c|}{ Intervention durationt } \\
\hline$\leq 3$ months & 14 & 1474 & $-47.51(-76.57$ to $-18.46 ; 81 \%)$ \\
\hline $3-6$ months & 11 & 2119 & $-15.20(-33.08$ to $2.68 ; 67 \%)$ \\
\hline$>6$ months & 9 & 2275 & $0.30(-17.83$ to $18.44 ; 61 \%)$ \\
\hline \multicolumn{4}{|l|}{$\begin{array}{l}\text { Follow-up } \\
\text { duration } \neq\end{array}$} \\
\hline$<3$ months & 17 & 1954 & $-42.17(-67.31$ to $-17.02 ; 84 \%)$ \\
\hline $3-6$ months & 13 & 2489 & $-22.29(-41.61$ to $-2.96 ; 77 \%)$ \\
\hline $7-12$ months & 11 & 2327 & $-26.60(-45.95$ to $-7.24 ; 73 \%)$ \\
\hline$>12$ months & 5 & 1264 & $-3.06(-34.05$ to $27.94 ; 83 \%)$ \\
\hline \multicolumn{4}{|l|}{$\begin{array}{l}\text { Intervention } \\
\text { setting }\end{array}$} \\
\hline Workplace & 8 & 1790 & $-8.93(-26.64$ to $8.78 ; 66 \%)$ \\
\hline Other & 26 & 4078 & $-28.21(-46.34$ to $-10.09 ; 80 \%)$ \\
\hline \multicolumn{4}{|l|}{ Assessment tool‡ } \\
\hline activPAL & 2 & 67 & $-45.37(-87.99$ to $-2.74 ; 76 \%)$ \\
\hline Actigraph & 4 & 334 & $-27.93(-70.71$ to $14.85 ; 75 \%)$ \\
\hline $\begin{array}{l}\text { Sitting time } \\
\text { questionnaire }\end{array}$ & 12 & 2576 & $-10.92(-30.59$ to $8.74 ; 57 \%)$ \\
\hline $\begin{array}{l}\text { Proxy measure } \\
\text { questionnaire }\end{array}$ & 17 & 2983 & $-29.39(-50.56$ to $-8.21 ; 84 \%)$ \\
\hline \multicolumn{4}{|l|}{ Intervention aim $\ddagger$} \\
\hline $\begin{array}{l}\text { SB Primary } \\
\text { outcome }\end{array}$ & 14 & 2258 & $-24.05(-45.43$ to $-2.67 ; 73 \%)$ \\
\hline $\begin{array}{l}\text { SB Secondary } \\
\text { outcome }\end{array}$ & 22 & 3764 & $-23.17(-40.02$ to $-6.32 ; 80 \%)$ \\
\hline \multicolumn{4}{|c|}{$\begin{array}{l}\text { *statistically significant subgroup difference at } \mathrm{p}<0.01 \text {. } \\
\text { tstatistically significant subgroup difference at } \mathrm{p}<0.05 \text {. } \\
\text { fnon-significant subgroup difference. } \\
\text { SB, sedentary behaviour. }\end{array}$} \\
\hline
\end{tabular}

three studies ${ }^{53} 7678$ and therefore assessed at high risk of bias related to the comparability of baseline groups. For the remaining studies, no formal assessment of the comparability of baseline groups was reported, and thus the risk of bias was 'unclear'.

\section{Reporting bias}

For half of the studies (26/51), access to a published study protocol or trial register was missing so that the risk of selective reporting was 'unclear'. However, nearly 50\% (24/51) of the studies were at low risk of selective outcome reporting. One study did not report all outcomes as stated in the study protocol and thus was at high risk of selective reporting. ${ }^{70}$

\section{Publication bias}

Lifestyle interventions were the only category of interventions where at least 10 studies were available and thus suitable for assessment of publication bias using the funnel plot (see online supplementary figure S1). The asymmetric distribution of effect sizes might indicate a publication bias towards studies with beneficial effects for reducing SB. However, an asymmetric funnel plot might be a study size effect.

\section{Effect of interventions}

\section{Primary outcomes}

The primary outcomes reported were overall time spent in SB as minutes per day $(n=49)$ or percentage of assessed time period $(n=3)$, number of sitting breaks $(n=3)$ and number of prolonged sitting events $(n=3)$.

Online supplementary table S1 summarises the original trial authors' conclusions of study outcomes. Twenty studies indicated a beneficial effect of interventions for reducing SB in favour of the intervention group. Of these, 10 studies employed a lifestyle intervention, ${ }^{29} 333437384251525474$ six studies targeted increase in PA, ${ }^{30} 4146486478$ two studies were combined PA/SB interventions ${ }^{32} 68$ and two studies were SB interventions. ${ }^{40} 63$ Two studies reported a beneficial intervention effect in favour of the control group; 3960 both studies were PA interventions. Control conditions were attention control ${ }^{60}$ and an alternative exercise treatment. ${ }^{39}$ Twenty-four studies suggested no evidence of a group difference in SB: 10 lifestyle interventions, $^{29} \quad 45 \quad 50 \quad 52 \quad 56 \quad 57 \quad 67 \quad 71 \quad 73 \quad 75$ seven PA interventions, 35364955586672 six PA/SB interventions, ${ }^{53} 6265707677$ and one SB intervention. ${ }^{44}$ Four studies-two lifestyle, ${ }^{47} 69$ one $\mathrm{PA} / \mathrm{SBs}^{43}{ }^{43}$ one dietary intervention ${ }^{61}$ — did not conclude on SB outcomes despite assessing SB.

A meta-analysis of 34 studies (5868 participants) suggested an overall reduction in sedentary time by mean differences (MD) of $-22.34 \mathrm{~min} /$ day $\left(95 \% \mathrm{CI}-35.81\right.$ to $-8.88, \mathrm{p}=0.001, \mathrm{I}^{2}=71 \%$ ) in favour of the intervention group. Figure 3 shows effect sizes of individual studies and pooled results by intervention type. Findings indicated a beneficial effect of interventions specifically targeting the reduction in SB as well as interventions employing a lifestyle intervention approach on reduced SB. Specific SB interventions ( $n=2,62$ participants) yielded an MD of $-41.76 \mathrm{~min} /$ day $\left(95 \%\right.$ CI -78.92 to $\left.-4.60, \mathrm{p}=0.003, \mathrm{I}^{2}=65 \%\right)$ and lifestyle
Figure 2 Risk of bias item presented as percentages across all studies.

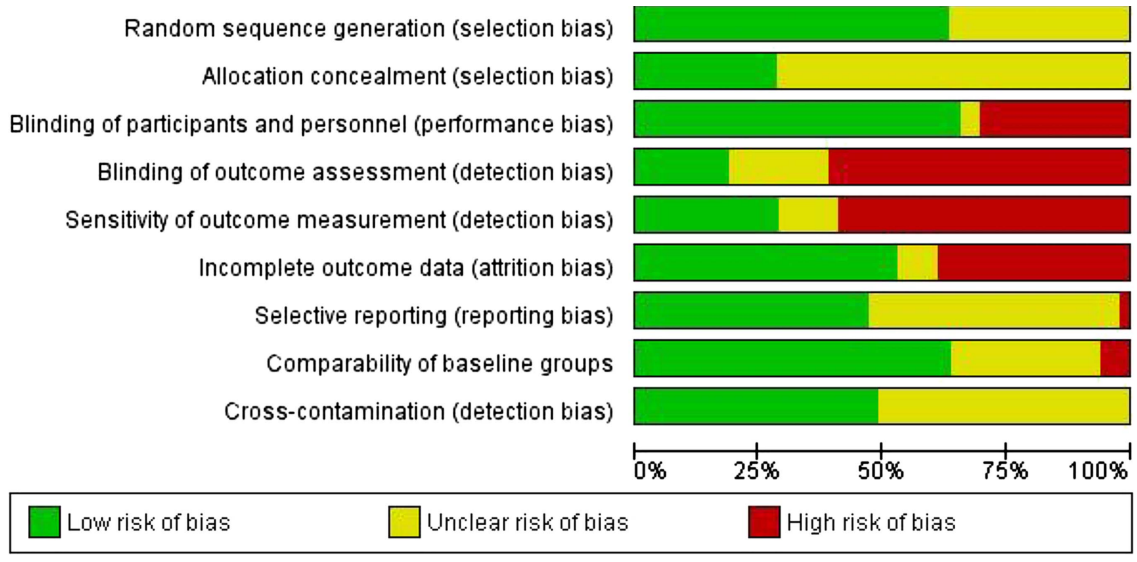

Random sequence generation (selection bias) Allocation concealment (selection bias) Blinding of participants and personnel (performance bias) Blinding of outcome assessment (detection bias) Incomplete outcome data (attrition bias) Selective reporting (reporting bias) Comparability of baseline groups ross-contamination (detection bias) 


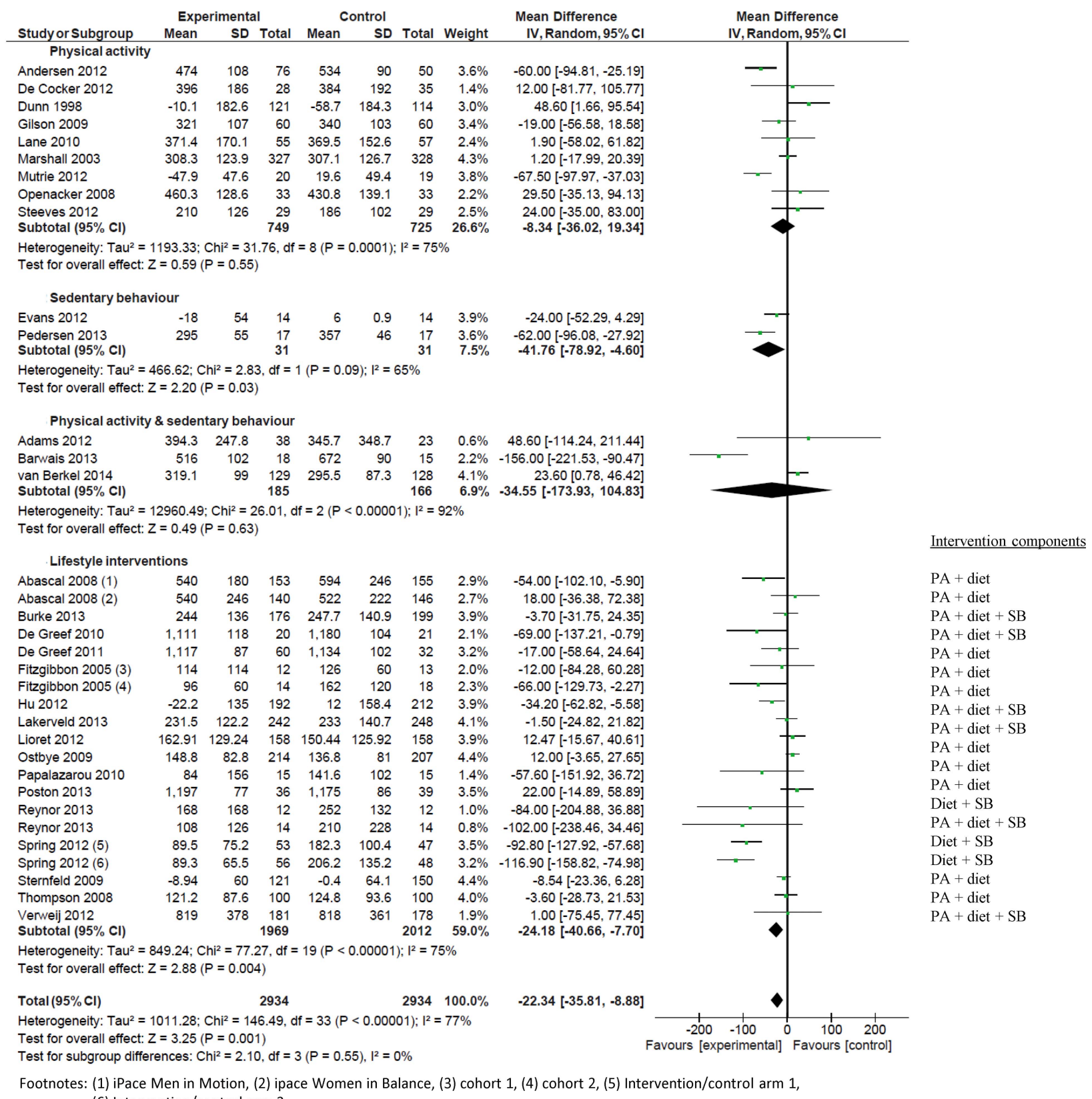
(6) Intervention/control arm 2

Figure 3 Forest plot of the intervention effect for reducing sitting time in minutes/day in adults by type of intervention. PA, physical activity; SB, sedentary behavior.

interventions ( $\mathrm{n}=20,3881$ participants) an MD of $-24.18 \mathrm{~min} /$ day $\left(95 \%\right.$ CI -40.66 to $\left.-7.70, p=0.004, I^{2}=75 \%\right)$. There was no evidence of a statistically significant effect of PA interventions or combined $\mathrm{PA} / \mathrm{SB}$ interventions for reducing $\mathrm{SB}$.

Pooled intervention effects on SB patterns indicated no statistically significant effect for both the number of sitting breaks per hour or the number of prolonged sitting events of more than $30 \mathrm{~min}$.

As indicated by the large $\mathrm{I}^{2}$ statistic, the level of statistical heterogeneity between studies was high. Subgroup analyses were conducted (defined a priori) to assess potential reasons for heterogeneity (table 1). A significant subgroup difference between assessed groups was detected for gender and intervention duration. Studies in men-only $(n=2 ; 434$ men), but not women-only ( $n=10 ; 1541$ women), resulted in significant intervention effects for reduced SB of intervention group participants $(\mathrm{MD} \quad-57.94 \mathrm{~min} / \mathrm{day}, \quad 95 \% \quad \mathrm{CI} \quad-86.14$ to $-29.74 \mathrm{~min} /$ day, $\mathrm{p}<0.001)$. The combined effects of mixed gender studies $(\mathrm{n}=22 ; 3393$ participants) also showed benefit in favour of the intervention group (MD $-25.32 \mathrm{~min} /$ day, $95 \% \mathrm{CI}$ -42.94 to $-7.69 \mathrm{~min} /$ day, $\mathrm{p}=0.005)$. Interventions of up to 3 months resulted in a significant reduction in sedentary time by an $\mathrm{MD}$ of $-47.51 \mathrm{~min} /$ day $(95 \% \mathrm{CI}-76.57$ to $-18.46 \mathrm{~min} /$ day, $\mathrm{p}=0.001,14$ studies, 1474 participants) in favour of the intervention group, whereas longer intervention durations of more than 3 months did not show beneficial intervention effects (table 1). Heterogeneity between studies could not be explained by follow-up duration, intervention setting, type of assessment tool and whether reducing SB was a primary or secondary aim of the study. However, subgroup analysis revealed that longterm effects of interventions were evident up to 12 months. The beneficial intervention effects attenuated at a follow-up duration 
of more than 12 months. All intervention settings except workplaces resulted in a significant reduction in SB in favour of the intervention group. Objective assessment of SB using an inclinometer and subjective assessment using proxy measure questionnaires resulted in a detection of a beneficial intervention effect. The overall intervention effect was not influenced by whether SB was a primary or secondary outcome (table 1 ).

Sensitivity analyses (see online supplementary tables S2-S5) show that results on SB for different types of interventions were not affected by inclusion of cluster RCTs, studies at high risk of attrition and performance bias, and studies with usual care or alternative treatment as the control group.

\section{Secondary outcomes}

Studies reported intervention effects on fasting blood glucose concentration, ${ }^{31} 4256$ glycosylated haemoglobin levels, ${ }^{37} 4269$ triglyceride levels, ${ }^{31} 42 \quad 56 \quad 69$ low-density lipoprotein levels, ${ }^{31425669}$ total cholesterol, ${ }^{37} 425669$ high-density lipoprotein levels, ${ }^{31} 394256 \quad 6469$ blood pressure, ${ }^{32} 38 \quad 4357596570$ BMI, ${ }^{29} \quad \begin{array}{llllllllllllll}33 & 36 & 37 & 42 & 55 & 56 & 57 & 58 & 59 & 62 & 64 & 69 & 74 & \text { waist }\end{array}$

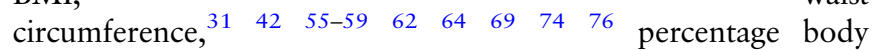
fat $^{42} 5556586264$ and mental health outcomes. ${ }^{29} 4148496472$ Some studies indicated a reduction in these secondary outcomes; however, studies were PA-only or lifestyle interventions and none of the studies were SB-only studies. Therefore, it is not possible to determine the intervention effect of reduced SB on cardiometabolic risk, body composition and mental health outcome. Specific SB studies did not assess the intervention effect on health outcomes. Meta-analysis results for each outcome are not reported here but are available from the authors.

\section{Quality of evidence}

Table 2 summarises the quality of evidence for reducing sedentary time by intervention type and duration. Owing to the intention of comparing different types of intervention with various control conditions, which was considered in the sensitivity analyses, the quality of evidence was not downgraded for indirectness or heterogeneity. Many plausible reasons for heterogeneity exist (eg, variation in population age, ethnicity, socioeconomic status).

\section{Lifestyle interventions}

The overall quality of evidence for lifestyle interventions was moderate with downgrading of the evidence by one level due to limitations in the design and implementation of the included studies.

\section{PA/SB interventions}

The overall quality of evidence of combined PA and SB interventions for reducing SB was moderate. The quality was downgraded by one level for high risk of bias in the majority of included studies.

\section{PA interventions}

Overall, the quality of PA intervention was moderate with the majority of studies having a high risk of detection and attrition bias.

\section{SB interventions}

The quality of evidence for reducing SB in adults was low based on the two studies available. The quality was downgraded twice for imprecision of results and high risk of performance bias. Participants and personnel were not blinded to the intervention intention.

\section{DISCUSSION}

\section{Summary of main findings}

There was clear evidence that it is possible to intervene to reduce SB in adults by $22 \mathrm{~min} /$ day in favour of the intervention group. Moderate to high-quality evidence on the efficacy of lifestyle interventions for reducing SB suggests that this may be a promising approach. Interventions focusing on SB only resulted in the greatest reduction in sedentary time (42 $\mathrm{min} /$ day); however, the quality of evidence was low and restricted to two studies only. Findings suggested that intervention durations up to 3 months and interventions targeting men and mixed genders can produce significant reductions in SB. There was no evidence that PA and combined $\mathrm{PA} / \mathrm{SB}$ interventions reduced SB. Evidence of intervention effects on changes in patterns of accumulation of SB was limited. Encouragingly, intervention effects were evident up to 12 months. Interventions in any setting except the workplace resulted in a significant reduction in SB in favour of the intervention group.

This systematic review sought to evaluate the evidence of effects of interventions which included SB as an outcome measure on cardiometabolic risk factors, body composition and mental health outcomes. Studies reporting these outcomes were PA or lifestyle interventions, and thus it was unclear whether any intervention effect was due to reduction in SB. Furthermore, the majority of studies that assessed health-related outcomes did not show a reduction in SB. However, improvement of health outcomes due to reduction of SB has been demonstrated in laboratory-based studies ${ }^{12}$ and a recently published community-based RCT. ${ }^{79}$

\section{Comparison of the findings with the literature}

Prince $e t a l^{23}$ published a systematic review on the effects of interventions for reducing SB in adults. Our findings are consistent with those of Prince et al in relation to the effect of $\mathrm{PA} / \mathrm{SB}$ interventions and interventions focusing on SB only, despite there being no overlap of included studies in the latter. The SB studies on which Prince et al based their main conclusion were excluded from this review because they either did not report a valid SB outcome measure ${ }^{80}$ or the intervention was not independent of the outcome (measuring TV viewing time while blocking TV function). ${ }^{81}$ In contrast to Prince et al, we found no evidence of a beneficial effect on SB from interventions focused on increasing PA. This difference in findings may be explained by six studies in our review being classed as lifestyle interventions while Prince et al classed them as PA interventions and one study being classed as a PA/SB intervention while Prince et al classed it as a PA intervention. Authors of future reviews should use precise categories of intervention types to identify the potential of single or multicomponent interventions (eg, lifestyle intervention which, in addition to $\mathrm{PA} / \mathrm{SB}$, also included a dietary/nutrition component) to reduce SB.

Other systematic reviews have been conducted with a focus on the effect of workplace interventions for reducing sitting time. ${ }^{82-84}$ Some findings are consistent ${ }^{82}$ with the findings of this study on the effect of workplace interventions to reduce SB while others were not. ${ }^{83}{ }^{84}$ Inconsistency can be explained by differences in inclusion criteria, since the majority of studies included in these reviews were not RCTs and thus did not qualify for our review. However, further high-quality RCTs investigating the effect of workplace interventions on sitting time are currently being conducted and publication of new evidence will follow shortly. ${ }^{85}$

\section{Implications for research and practice}

Findings from lifestyle interventions and studies focusing on reducing $\mathrm{SB}$ are promising. While this is encouraging, $\mathrm{SB}$ are 
Table 2 GRADE assessment of quality of evidence

\begin{tabular}{|c|c|c|c|}
\hline Outcomes & $\begin{array}{l}\text { Illustrative comparative risks* }(95 \% \mathrm{Cl}) \\
\text { Corresponding risk } \\
\text { Interventions for reducing sedentary behaviour }\end{array}$ & $\begin{array}{l}\text { Number of } \\
\text { Participants (studies) }\end{array}$ & $\begin{array}{l}\text { Quality of the } \\
\text { evidence (GRADE) }\end{array}$ \\
\hline Effect of lifestyle interventions & $\begin{array}{l}\text { The mean effect of lifestyle interventions in the intervention groups was } \\
24.18 \mathrm{~min} / \text { day lower ( } 40.66 \text { to } 7.70 \text { lower) }\end{array}$ & 3981 (20 studies) & $\oplus \oplus \oplus \ominus$ moderate $\dagger$ \\
\hline $\begin{array}{l}\text { Intervention duration } \\
\leq 3 \text { months }\end{array}$ & $\begin{array}{l}\text { The mean effect of lifestyle interventions-intervention duration } \leq 3 \text { months in } \\
\text { the intervention groups was } 97.75 \mathrm{~min} / \text { day lower (121.88 to } 73.61 \text { lower) }\end{array}$ & 297 (5 studies) & $\oplus \oplus \oplus \oplus$ high \\
\hline $\begin{array}{l}\text { Intervention duration } \\
3-6 \text { months }\end{array}$ & $\begin{array}{l}\text { The mean effect of lifestyle interventions-intervention duration 3-6 months in } \\
\text { the intervention groups was } 8.42 \text { min/day lower (19.05 lower to } 2.21 \text { higher) }\end{array}$ & 1664 (7 studies) & $\oplus \oplus \oplus \ominus$ moderate \\
\hline $\begin{array}{l}\text { Intervention duration } \\
>6 \text { months }\end{array}$ & $\begin{array}{l}\text { The mean effect of lifestyle interventions-intervention duration }>6 \text { months in } \\
\text { the intervention groups was } 3.99 \text { min/day lower (21.93 lower to } 13.96 \text { higher) }\end{array}$ & 2040 (8 studies) & $\oplus \oplus \oplus \ominus$ moderate $\dagger$ \\
\hline $\begin{array}{l}\text { Effect of physical activity/ } \\
\text { sedentary behaviour } \\
\text { interventions }\end{array}$ & $\begin{array}{l}\text { The mean effect of physical activity/sedentary behaviour interventions in the } \\
\text { intervention groups was } 32.51 \mathrm{~min} / \text { day lower ( } 106.52 \text { lower to } 41.50 \text { higher) }\end{array}$ & 471 (4 studies) & $\oplus \oplus \oplus \ominus$ moderate \\
\hline $\begin{array}{l}\text { Intervention duration } \\
\leq 3 \text { months }\end{array}$ & $\begin{array}{l}\text { The mean effect of physical activity/sedentary behaviour interventions- } \\
\text { intervention duration } \leq 3 \text { months in the intervention groups was } 54.69 \mathrm{~min} / \text { day } \\
\text { lower ( } 166.60 \text { lower to } 57.22 \text { higher) }\end{array}$ & 214 (3 studies) & $\oplus \Theta \Theta \Theta$ very low§`ף \\
\hline $\begin{array}{l}\text { Intervention duration 3-6 } \\
\text { months }\end{array}$ & $\begin{array}{l}\text { The mean effect of physical activity/sedentary behaviour interventions- } \\
\text { intervention duration } 3-6 \text { months in the intervention groups was } 23.60 \mathrm{~min} / \text { day } \\
\text { higher ( } 0.78 \text { higher to } 46.42 \text { higher) }\end{array}$ & 257 (1 study) & $\oplus \oplus \oplus \Theta$ moderate** \\
\hline $\begin{array}{l}\text { Intervention duration } \\
>6 \text { months }\end{array}$ & No evidence available & $0(0)$ & $\begin{array}{l}\text { No evidence } \\
\text { available }\end{array}$ \\
\hline $\begin{array}{l}\text { Effect of physical activity } \\
\text { interventions }\end{array}$ & $\begin{array}{l}\text { The mean effect of physical activity interventions in the intervention groups was } \\
6.08 \mathrm{~min} / \text { day lower ( } 38.00 \text { lower to } 25.84 \text { higher) }\end{array}$ & 1354 (8 studies) & $\oplus \oplus \oplus \ominus$ moderatet $\dagger$ \\
\hline $\begin{array}{l}\text { Intervention duration } \\
\leq 3 \text { months }\end{array}$ & $\begin{array}{l}\text { The mean effect of physical activity interventions-intervention duration } \\
\leq 3 \text { months in the intervention groups was } 10.43 \mathrm{~min} / \text { day lower ( } 49.85 \text { lower to } \\
28.98 \text { higher) }\end{array}$ & 935 (5 studies) & $\oplus \oplus \oplus \ominus$ moderatet† \\
\hline $\begin{array}{l}\text { Intervention duration } \\
3-6 \text { months }\end{array}$ & $\begin{array}{l}\text { The mean effect of physical activity interventions-intervention duration 3- } \\
6 \text { months in the intervention groups was } 21.52 \mathrm{~min} / \text { day lower (103.55 lower to } \\
60.51 \text { higher) }\end{array}$ & 184 (2 studies) & $\oplus \oplus \oplus \ominus$ moderate $\dagger$ \\
\hline $\begin{array}{l}\text { Intervention duration } \\
>6 \text { months }\end{array}$ & $\begin{array}{l}\text { The mean effect of physical activity interventions-intervention duration } \\
>6 \text { months in the intervention groups was } 48.60 \text { min/day higher (1.66 to } 95.54 \\
\text { higher) }\end{array}$ & 235 (1 study) & $\oplus \oplus \oplus \ominus$ moderate $\ddagger$ \\
\hline $\begin{array}{l}\text { Effect of sedentary behaviour } \\
\text { interventions }\end{array}$ & $\begin{array}{l}\text { The mean effect of sedentary behaviour interventions in the intervention groups } \\
\text { was } 41.76 \mathrm{~min} / \text { day lower ( } 78.92 \text { to } 4.60 \text { lower) }\end{array}$ & 62 (2 studies) & $\oplus \oplus \Theta \Theta$ low§'§§ \\
\hline $\begin{array}{l}\text { Intervention duration } \\
\leq 3 \text { months }\end{array}$ & $\begin{array}{l}\text { The mean effect of sedentary behaviour interventions-intervention duration } \\
\leq 3 \text { months in the intervention groups was } 41.76 \mathrm{~min} / \text { day lower (78.92 to } 4.60 \\
\text { lower) }\end{array}$ & 62 (2 studies) & $\oplus \oplus \Theta \Theta$ low§'§§ \\
\hline $\begin{array}{l}\text { Intervention duration } \\
3-6 \text { months }\end{array}$ & No evidence available & $0(0)$ & $\begin{array}{l}\text { No evidence } \\
\text { available }\end{array}$ \\
\hline $\begin{array}{l}\text { Intervention duration } \\
>6 \text { months }\end{array}$ & No evidence available & $0(0)$ & $\begin{array}{l}\text { No evidence } \\
\text { available }\end{array}$ \\
\hline 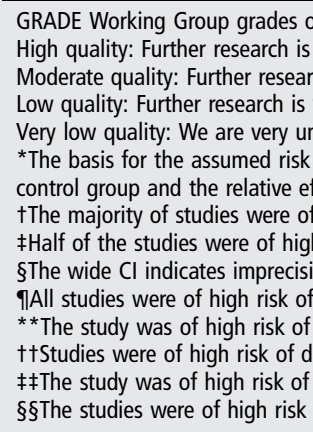 & $\begin{array}{l}\text { evidence. } \\
\text { ary unlikely to change our confidence in the estimate of effect. } \\
\text { is likely to have an important impact on our confidence in the estimate of effect and ma } \\
\text { ry likely to have an important impact on our confidence in the estimate of effect and is lit } \\
\text { ertain about the estimate. } \\
\text { g, the median control group risk across studies) is provided in footnotes. The correspondi } \\
\text { ct of the intervention (and its } 95 \% \mathrm{Cl}) \text {. } \\
\text { igh risk of selection, performance or detection bias. } \\
\text { isk for performance bias (no blinding of participants or personnel to the intervention inte } \\
\text { of results. } \\
\text { erformance bias and more than half showed high risk of attrition. } \\
\text { lection bias. } \\
\text { ection or attrition bias. } \\
\text { tection bias. } \\
\text { performance bias, that is, participants and personnel were not blinded. }\end{array}$ & $\begin{array}{l}\text { change the estimate. } \\
\text { ely to change the estimate. } \\
\text { g risk (and its } 95 \% \mathrm{Cl} \text { ) is ba }\end{array}$ & ed on the assumed risk in the \\
\hline
\end{tabular}

health-related behaviours and part of a pathway to better health outcomes. More high-quality research is needed that includes clinical health outcome measures. However, the findings of this review should encourage clinicians and public health practitioners to provide advice on how to reduce total volume of sitting time and breaking up long periods of sitting. This advice should not diminish or replace advice on achieving the recommended levels of MVPA. It is somewhat surprising that interventions that targeted PA alone, or even PA and SB, appeared to be less effective in reducing SB. This suggests that attention needs to be paid to the ways in which SB are targeted in these interventions. For example, it may be important to improve knowledge about the independent health risks of SB and to highlight the risk of compensatory behaviour (eg, a feeling that you have earned the right to be sedentary because you went for a brisk walk earlier). Given the evidence that increased breaks in SB are associated with improved health status, consensus is needed on the most appropriate SB patterning descriptors to use which are 
sensitive to intervention (eg, 'breaking rate' or time spent/ number of longer sedentary events). New interventions should also be developed around technologies that allow people to monitor their SB in addition to their physical activity to support them in setting goals to reduce their SB and increase PA.

The majority of studies included in the meta-analyses assessed intervention effects using self-report. While self-report measures are pragmatic and may provide contextual information, they have limitations in terms of accuracy. Subgroup analysis revealed that objective assessment of SB using a posture measurement tool such as the activ PAL and subjective assessment using proxy measure questionnaires (captures context specific sitting time) resulted in the detection of a beneficial intervention effect. Assessment tools that measure posture might be more valid and reliable in measuring SB and thus detecting intervention effects compared to estimation of SB via accelerometry (eg, ActiGraph). Therefore, researchers and practitioners should use posture measurement tools and context specific measurement tools which may prompt a reliable cognitive recall of sedentary behaviour.

Heterogeneity between studies was only partly explained by differences of studies in gender and intervention duration. Further work is warranted to identify the 'active ingredients' of the successful interventions and to explore the specific behaviour change techniques employed as well as barriers and facilitators of SB interventions. General principles for development of interventions to reduce SB have been established drawing from behavioural research on physical activity. ${ }^{86}$ Examples include evaluating interventions designed for very specific contexts (work environments at home) and using behaviour change theory and associated techniques ${ }^{87}$ to systematically understand and change SB in different groups and settings.

Additionally, future studies should consider the influence of gender, given that some cohort studies suggested deleterious relationships of SB with health outcomes to be more pronounced in women than men. However, based on our review evidence, interventions with the potential to reduce SB showed limited effects when targeting women. Limited evidence was available on intervention effects on sedentary time in older adults.

\section{Strengths and limitations}

The systematic and transparent methods reported here reduce identification and selection bias. The inclusion criteria used for study designs (only RCTs) meant that the risk of bias was reduced. Overall, the robust methods used in this review ensure that the results and conclusions are likely to be as truly valid and replicable as possible. Subgroup and sensitivity analyses enabled a more nuanced understanding and interpretation of the results, as well as exploring the effect of potentially influential variables. Lastly, our exploration of the clinical outcomes was a strength, and led to the identification of research gaps which should be addressed in future RCTs.

One limitation was that no subgroup analysis for age was undertaken because there were too few studies in older adults.

\section{CONCLUSION}

There was evidence that it is possible to intervene to reduce SB in adults by around $22 \mathrm{~min} /$ day. Lifestyle interventions and those targeting SB only may be promising approaches, but more highquality research is needed. More research is also needed to determine if SB interventions are sufficient to produce clinically meaningful and sustainable reductions in sedentary time. Further work is needed to identify the 'active' intervention components.

\section{What are the new findings?}

- Interventions targeting sedentary behaviour (SB) and lifestyle interventions can reduce sedentary time in adults.

- Interventions targeting an increase in physical activity and interventions combining an increase of physical activity with reducing sedentary behaviour did not reduce sedentary time in adults.

- We do not yet know if effective interventions for reducing sedentary behaviour result in clinically meaningful and sustained improvements in health outcomes.

How might it impact on clinical and public health practice in the near future?

- The findings of this study (together with the broader body of relevant evidence) do not point to specific recommendations on the degree of reduction in sitting time required to deliver significant health benefits. Nevertheless, the findings should encourage clinicians and public health practitioners to provide advice about reducing the total volume of sitting time and breaking up long periods of sitting by demonstrating that such advice can be effective. This advice should not diminish or replace advice on achieving recommended levels of physical activity.

- Interventions with a focus on physical activity should provide additional emphasis on the importance of and barriers to reducing SB. New technologies should be developed to allow self-monitoring and goal setting around SB as well as physical activity.

- Awareness will be raised on the topic of sedentary behaviour and its impact on health.

- Interventions that target sedentary behaviour will be developed and tested.

- Further research is needed to determine the clinical significance of changing patterns of sedentary behaviour.

Twitter Follow Nanette Mutrie at @nanettemutrie

Acknowledgements The EuroFIT Consortium is acknowledged for their support and contribution in the development of this review. In particular, the authors thank Professor Sally Wyke and Dr Jason Gill for helpful comments on a preliminary report to the consortium. This manuscript also benefited from helpful reviewer comments.

\section{Collaborators EuroFIT consortium.}

Contributors AM, NM, DHS, RJ and CF led the review on behalf of the EuroFIT consortium. AM, NM, DHS, CF and RJ conceived of the systematic review strategy. AM wrote the protocol and all authors refined and approved it. AM conducted the review and screened the initial results. AM, DHS, RJ, CF and NM appraised and extracted data from the primary studies and analysed the findings. AM drafted the manuscript and all authors contributed to the critical revision of the manuscript and approved the final revised version. NM is the guarantor.

Funding This review was conducted on behalf of the EuroFIT consortium (see http://eurofitfp7.eu). EuroFIT is funded by the European Community's Framework Programme Seven (FP7) under contract No. 602170'EuroFIT.

Competing interests None.

Provenance and peer review Not commissioned; externally peer reviewed. 


\section{REFERENCES}

1 Barnes J, Behrens TK, Benden ME, et al. Letter to the editor: standardized use of the terms "sedentary" and "sedentary behaviours." App/ Physiol Nutr Metab-Physiol Appliquee Nutr Et Metabolisme 2012;37:540-2.

2 Owen N, Salmon J, Koohsari MJ, et al. Sedentary behaviour and health: mapping environmental and social contexts to underpin chronic disease prevention. $\mathrm{Br} J$ Sports Med 2014;48:174-7.

3 de Rezende LF, Rodrigues Lopes M, Rey-López JP, et al. Sedentary behavior and health outcomes: an overview of systematic reviews. PLOS ONE 2014;9:e105620.

4 Dempsey PC, Owen N, Biddle SJ, et al. Managing sedentary behavior to reduce the risk of diabetes and cardiovascular disease. Curr Diab Rep 2014;14:1-11.

5 Dunstan DW, Howard B, Healy GN, et al. Too much sitting - a health hazard. Diabetes Res Clin Pract 2012;97:368-76.

6 Katzmarzyk PT, Church TS, Craig CL, et al. Sitting time and mortality from all causes, cardiovascular disease, and cancer. Med Sci Sports Exerc 2009:41:998-1005.

7 Matthews CE, George SM, Moore SC, et al. Amount of time spent in sedentary behaviors and cause-specific mortality in US adults. Am J Clin Nutr 2012;95:437-45.

8 Seguin R, Buchner DM, Liu J, et al. Sedentary behavior and mortality in older women: the Women's Health Initiative. Am J Prev Med 2014;46:122-35.

9 Van der Ploeg HP, Chey T, Korda RJ, et al. Sitting time and all-cause mortality risk in 222497 Australian adults. Arch Intern Med 2012;172:494-500.

10 Healy GN, Dunstan DW, Salmon J, et al. Breaks in sedentary time: beneficial associations with metabolic risk. Diabetes Care 2008;31:661-6.

11 Bailey DP, Locke CD. Breaking up prolonged sitting with light-intensity walking improves postprandial glycemia, but breaking up sitting with standing does not. J Sci Med Sport 2014;pii: S1440-2440(14)00051-6

12 Peddie MC, Bone JL, Rehrer NJ, et al. Breaking prolonged sitting reduces postprandial glycemia in healthy, normal-weight adults: a randomized crossover trial. Am J Clin Nutr 2013;98:358-66.

13 Dunstan DW, Kingwell BA, Larsen $\mathrm{R}$, et al. Breaking up prolonged sitting reduces postprandial glucose and insulin responses. Diabetes Care 2012;35:976-83.

14 Proper $\mathrm{Kl}$, Singh AS, van Mechelen $\mathrm{W}$, et al. Sedentary behaviors and health outcomes among adults a systematic review of prospective studies. Am J Prev Med 2011:40:174-82

15 Rezende LF, Rey-Lopez J, Matsudo VK, et al. Sedentary behavior and health outcomes among older adults: a systematic review. BMC Public Health 2014;14:333.

16 Chau JY, Grunseit AC, Chey T, et al. Daily sitting time and all-cause mortality: a meta-analysis. PLOS ONE 2013;8:e80000.

17 Thorp AA, Owen N, Neuhaus M, et al. Sedentary behaviors and subsequent health outcomes in adults: a systematic review of longitudinal studies, 1996-2011. Am J Prev Med 2011;41:207-15.

18 Wilmot E, Edwardson C, Achana F, et al. Sedentary time in adults and the association with diabetes, cardiovascular disease and death: systematic review and meta-analysis. Diabetologia 2012;55:2895-905.

19 Healy GN, Clark BK, Winkler EA, et al. Measurement of adults' sedentary time in population-based studies. Am J Prev Med 2011;41:216-27.

20 Harvey J, Chastin S, Skelton D. Prevalence of sedentary behavior in older adults: a systematic review. Int J Environ Res Public Health 2013;10:6645-61.

21 Rhodes RE, Mark RS, Temmel CP. Adult sedentary behavior: a systematic review. Am J Prev Med 2012;42:e3-28.

22 Biddle SJ, Petrolini I, Pearson N. Interventions designed to reduce sedentary behaviours in young people: a review of reviews. Br J Sports Med 2014;48:182-6.

23 Prince SA, Saunders TJ, Gresty K, et al. A comparison of the effectiveness of physical activity and sedentary behaviour interventions in reducing sedentary time in adults: a systematic review and meta-analysis of controlled trials. Obes Rev 2014;15:905-19.

24 Martin A, Saunders D, Jepson $R$, et al. Interventions to influence sedentary behaviour in adults: systematic review and meta-analysis. http://www.crd.york.ac.uk/ PROSPERO_REBRANDING/display_record.asp?ID=CRD42014007064: PROSPERO International prospective register of systematic reviews, 2014

25 Higgins JPT, Green S. eds. Cochrane handbook for systematic reviews of interventions version 5.1.0 [updated March 2011]. The Cochrane Collaboration, 2011.

26 GRADEpro [program]. 3.2 for Windows version, 2008

27 Review Manager [program]. 5.2 version. Copenhagen: The Nordic Cochrane Centre, The Cochrane Collaboration, 2012.

28 Aadahl M, Linneberg A, Witte $D$, et al. Reduction of sitting time in sedentary men and women. A randomized controlled trial (Sedentary Intervention Trial). J Sci Med Sport 2012;15:S302--303.

29 Abascal LB. The effect of depression and adherence in a dietary and physical activity intervention for overweight and obese adults. Dissertation Abstracts International: Section B: The Sciences and Engineering 2008;69(4-B):2614.

30 Allen NA, Fain JA, Braun B, et al. Continuous glucose monitoring counseling improves physical activity behaviors of individuals with type 2 diabetes: a randomized clinical trial. Diabetes Res Clin Pract 2008;80:371-9.
31 Andersen E, Burton NW, Anderssen SA. Physical activity levels six months after a randomised controlled physical activity intervention for Pakistani immigrant men living in Norway. Int J Behav Nutr Phys Act 2012;9:47.

32 Barwais FA, Cuddihy TF, Tomson LM. Physical activity, sedentary behavior and tota wellness changes among sedentary adults: a 4-week randomized controlled trial. Health Qual Life Outcomes 2013;11:183.

33 Burke L, Lee AH, Jancey J, et al. Physical activity and nutrition behavioural outcomes of a home-based intervention program for seniors: a randomized controlled trial. Int J Behav Nutr Phys Act 2013;10:14.

34 Carlson JA, Sallis JF, Ramirez ER, et al. Physical activity and dietary behavior change in Internet-based weight loss interventions: comparing two multiple-behavior change indices. Prev Med 2012;54:50-4.

35 Chin A Paw MJ, van Poppel MN, et al. Effects of resistance and functional-skills training on habitual activity and constipation among older adults living in long-term care facilities: a randomized controlled trial. BMC Geriatr 2006;6:9. http:/l onlinelibrary.wiley.com/o/cochrane/clcentral/articles/914/CN-00566914/frame.html

36 De Cocker K, Spittaels H, Cardon G, et al. Web-based, computer-tailored, pedometer-based physical activity advice: development, dissemination through general practice, acceptability, and preliminary efficacy in a randomized controlled trial. J Med Internet Res 2012;14:e53.

37 De Greef K, Deforche B, Tudor-Locke C, et al. A cognitive-behavioural pedometer-based group intervention on physical activity and sedentary behaviour in individuals with type 2 diabetes. Health Educ Res 2010;25:724-36.

38 De Greef KP, Deforche BI, Ruige JB, et al. The effects of a pedometer-based behavioral modification program with telephone support on physical activity and sedentary behavior in type 2 diabetes patients. Patient Educ Couns 2011;84:275-9.

39 Dunn AL, Marcus BH, Kampert JB, et al. Comparison of lifestyle and structured interventions to increase physical activity and cardiorespiratory fitness: a randomized trial. JAMA 1999;281:327-34.

40 Evans RE, Fawole HO, Sheriff SA, et al. Point-of-choice prompts to reduce sitting time at work: a randomized trial. Am J Prev Med 2012;43:293-7.

41 Fitzsimons CF, Baker G, Gray SR, et al. Does physical activity counselling enhance the effects of a pedometer-based intervention over the long-term: 12-month findings from the Walking for Wellbeing in the west study. BMC Public Health 2012;12:206.

$42 \mathrm{Hu} \mathrm{G}$, Tian H, Zhang F, et al. Tianjin Gestational Diabetes Mellitus Prevention Program: study design, methods, and 1-year interim report on the feasibility of lifestyle intervention program. Diabetes Res Clin Pract 2012;98:508-17

43 Jago R, Sebire SJ, Turner KM, et al. Feasibility trial evaluation of a physical activity and screen-viewing course for parents of 6 to 8 year-old children: teamplay. Int J Behav Nutr Phys Act. 2013;10:31. http://onlinelibrary.wiley.com/o/cochrane/ clcentral/articles/090/CN-00864090/frame.html

44 Judice PB, Matias CN, Santos DA, et al. Caffeine intake, short bouts of physical activity, and energy expenditure: a double-blind randomized crossover trial. PLOS ONE 2013:8:e68936.

45 Lakerveld J, Bot SDM, Van der Ploeg HP, et al. The effects of a lifestyle intervention on leisure-time sedentary behaviors in adults at risk: the Hoorn Prevention Study, a randomized controlled trial. Prev Med 2013;57:351-6.

46 Marshall AL, Leslie ER, Bauman AE, et al. Print versus website physical activity programs: a randomized trial. Am J Prev Med 2003;25:88-94.

47 McGuire MT, Jeffery RW, French SA, et al. The relationship between restraint and weight and weight-related behaviors among individuals in a community weight gain prevention trial. Int J Obes Relat Metab Disord 2001;25:574-80.

48 Mutrie N, Doolin O, Fitzsimons CF, et al. Increasing older adults' walking through primary care: results of a pilot randomized controlled trial. Fam Pract 2012;29:633-42.

49 Opdenacker J, Boen F. Effectiveness of face-to-face versus telephone support in increasing physical activity and mental health among university employees. J Phys Act Health 2008; 5:830-43.

50 Ostbye T, Krause KM, Lovelady CA, et al. Active Mothers Postpartum: a randomized controlled weight-loss intervention trial. Am J Prev Med 2009:37:173-80

51 Papalazarou A, Yannakoulia M, Kavouras SA, et al. Lifestyle intervention favorably affects weight loss and maintenance following obesity surgery. Obesity 2010;18:1348-53.

52 Raynor HA, Steeves EA, Bassett DR Jr, et al. Reducing TV watching during adult obesity treatment: two pilot randomized controlled trials. Behav Ther 2013;44:674-85

53 Slootmaker SM, Chinapaw MJM, Schuit AJ, et al. Feasibility and effectiveness of online physical activity advice based on a personal activity monitor: randomized controlled trial. J Med Internet Res 2009;11:e27.

54 Spring B, Schneider K, McFadden HG, et al. Multiple behavior changes in diet and activity: a randomized controlled trial using mobile technology. Arch Intern Med 2012;172:789-96.

55 Steeves JA, Bassett DR, Fitzhugh EC, et al. Can sedentary behavior be made more active? A randomized pilot study of TV commercial stepping versus walking. Int J Behav Nutr Phys Act 2012;9:95. 
56 Thompson JL, Allen $\mathrm{P}$, Helitzer DL, et al. Reducing diabetes risk in American Indian women. Am J Prev Med 2008;34:192-201.

57 Fitzgibbon ML, Stolley MR, Schiffer L, et al. A combined breast health/weight loss intervention for Black women. Prev Med 2005;40:373-83. http://onlinelibrary.wiley. com/o/cochrane/clcentral/articles/377/CN-00511377/frame.html

58 Hansen AW, Grønbæk M, Helge JW, et al. Effect of a web-based intervention to promote physical activity and improve health among physically inactive adults: a population-based randomized controlled trial. J Med Internet Res 2012;14:e145. http://onlinelibrary.wiley.com/o/cochrane/clcentral/articles/871/CN-00841871/frame. html

59 Katzmarzyk PT, Champagne CM, Tudor-Locke C, et al. A short-term physical activity randomized trial in the lower Mississippi delta. PLOS ONE 2011;6:e26667.

60 Lane A, Murphy N, Bauman A, et al. Randomized controlled trial to increase physical activity among insufficiently active women following their participation in a mass event. Health Educ J 2010;69:287-96.

61 López-Fontana CM, Sánchez-Villegas A, Martínez-Gonzalez MA, et al. Daily physical activity and macronutrient distribution of low-calorie diets jointly affect body fat reduction in obese women. Appl Physiol Nutr Metab 2009;34:595-602. http://onlinelibrary.wiley.com/o/cochrane/clcentral/articles/007/ CN-00722007/frame.html

62 Kallings LV, Sierra Johnson J, Fisher RM, et al. Beneficial effects of individualized physical activity on prescription on body composition and cardiometabolic risk factors: results from a randomized controlled trial. Eur J Cardiovasc Prev Rehabil 2009;16:80-4.

63 Pedersen SJ, Cooley PD, Mainsbridge C. An e-health intervention designed to increase workday energy expenditure by reducing prolonged occupational sitting habits. Work 2014;49:289-95.

64 Baker G, Gray SR, Wright A, et al; Scottish Physical Activity Research Collaboration (SPARColl). The effect of a pedometer-based community walking intervention "Walking for Wellbeing in the West" on physical activity levels and health outcomes: a 12-week randomized controlled trial. Int J Behav Nutr Phys Act 2008;5:44.

65 Gilson ND, Puig-Ribera A, McKenna J, et al. Do walking strategies to increase physical activity reduce reported sitting in workplaces: a randomized control trial. Int J Behav Nutr Phys Act 2009;6:43.

66 Morrison R, Reilly JJ, Penpraze V, et al. Children, parents and pets exercising together (CPET): exploratory randomised controlled trial. BMC Public Health 2013;13:1096.

67 Poston L, Briley AL, Barr S, et al. Developing a complex intervention for diet and activity behaviour change in obese pregnant women (the UPBEAT trial); assessment of behavioural change and process evaluation in a pilot randomised controlled trial. BMC Pregnancy Childbirth 2013;13:148.

68 Robertson MM, Ciriello VM, Garabet AM. Office ergonomics training and a sit-stand workstation: effects on musculoskeletal and visual symptoms and performance of office workers. Appl Ergon 2013;44:73-85.

69 Canuto K, Cargo M, Li M, et al. Pragmatic randomised trial of a 12-week exercise and nutrition program for Aboriginal and Torres Strait Islander women: clinical results immediate post and 3 months follow-up. BMC Public Health 2012;12:933.
70 van Berkel J, Boot CR, Proper Kl, et al. Effectiveness of a worksite mindfulness-based multi-component intervention on lifestyle behaviors. Int J Behav Nutr Phys Act 2014;11:9.

71 Lioret S, Campbell KJ, Crawford D, et al. A parent focused child obesity prevention intervention improves some mother obesity risk behaviors: the Melbourne infant program. Int J Behav Nutr Phys Act 2012;9:100

72 Rosenberg DE. Outcomes of a multilevel walking intervention for older adults living in retirement communities. Dissertation Abstracts International: Section B: The Sciences and Engineering 2011;71(8-B):5143.

73 Sternfeld B, Block C, Quesenberry CP Jr, et al. Improving diet and physical activity with ALIVE: a worksite randomized trial. Am J Prev Med 2009;36:475-83.

74 Verweij LM, Proper KI, Weel ANH, et al. The application of an occupational health guideline reduces sedentary behaviour and increases fruit intake at work: results from an RCT. Occup Environ Med 2012;69:500-7.

75 Anand SS, Davis AD, Ahmed R, et al; SHARE-AP ACTION Investigators. A family-based intervention to promote healthy lifestyles in an aboriginal community in Canada. Can J Public Health 2007;98:447-52.http://onlinelibrary.wiley.com/o/ cochrane/clcentral/articles/774/CN-00668774/frame.html

76 Adams MM. On our feet: feasibility trial of an intervention to reduce sedentary behavior and increase physical activity. Dissertation Abstracts International: Section B: The Sciences and Engineering 2013;73:(10-B(E)): No Pagination Specified.

77 Parry S, Straker L, Gilson ND, et al. Participatory workplace interventions can reduce sedentary time for office workers - a randomised controlled trial. PLOS ONE 2013;8: e78957.

78 Andersen E, Høstmark AT, Anderssen SA. Effect of a physical activity intervention on the metabolic syndrome in Pakistani immigrant men: a randomized controlled trial. J Immigr Minor Health 2012;14:738-46. http://onlinelibrary.wiley.com/o/cochrane/ clcentral/articles/646/CN-00848646/frame.html

79 Aadahl M, Linneberg A, Møller TC, et al. Motivational counseling to reduce sitting time. Am J Prev Med 2014;47:576-86.

80 Carr LJ, Karvinen K, Peavler $M$, et al. Multicomponent intervention to reduce daily sedentary time: a randomised controlled trial. BMJ Open 2013;3:e003261.

81 Otten JJ, Jones KE, Littenberg $B$, et al. Effects of television viewing reduction on energy intake and expenditure in overweight and obese adults: a randomized controlled trial. Arch Intern Med 2009;169:2109-15.

82 Chau JY, der Ploeg HP, van Uffelen JG, et al. Are workplace interventions to reduce sitting effective? A systematic review. Prev Med 2010;51:352-6.

83 Neuhaus M, Eakin EG, Straker L, et al. Reducing occupational sedentary time: a systematic review and meta-analysis of evidence on activity-permissive workstations. Obes Rev 2014;15:822-38.

84 Torbeyns T, Bailey S, Bos I, et al. Active workstations to fight sedentary behaviour. Sports Med 2014;44:1261-73.

85 Shrestha N, ljaz S, Kukkonen-Harjula Katriina T, et al. Workplace interventions for reducing sitting at work. Cochrane Database Syst Rev 2015;1:CD010912. http:/l onlinelibrary.wiley.com/doi/10.1002/14651858.CD010912/abstract

86 Owen N, Sugiyama T, Eakin EE, et al. Adults' sedentary behavior: determinants and interventions. Am J Prev Med 2011;41:189-96.

87 Michie S, Johnston M. Theories and techniques of behaviour change: developing a cumulative science of behaviour change. Health Psychol Rev 2012;6:1-6. 